Bangladesh J. Bot. 48(2): 345-352, 2019 (June)

\title{
ANTIMICROBIAL, ANTIOXIDANT, ANTI-TYROSINASE AND ANTI-UREASE ACTIVITIES AND FT-IR ANALYSES OF HELICHRYSUM GRAVEOLENS (BIEB) SWEET
}

\author{
Sinem Aydin* \\ Giresun Unvversity, Department of Biology, Giresun, Turkey \\ Keywords: Helichrysum graveolens, Antioxidant, Enzyme inhibition
}

\begin{abstract}
Helichrysum graveolens (Bieb) Sweet possesses various medicinal applications such as diuretic, treatment of the sand and stone in kidney, regulation of digestion problems and strenghtening of the immune system. The investigation was carried out to reveal ethanol extracts of flower and stem parts of $H$. graveolens for antimicrobial, antioxidant, anti-tyrosinase and anti-urease activities. Ethanol extract of stem part of $H$. graveolens exhibited more antibacterial activity against growth of bacteria except for K. pneumoniae. Stem part of $H$. graveolens has higher copper reducing antioxidant capacity (CUPRAC) and anti-urease activities than flower part of $H$. graveolens. Anti-tyrosinase activity ( $\mathrm{IC}_{50}$ values) of stem and flower parts of $H$. graveolens was found to be $0.01549 \pm 0.0006 \mu \mathrm{g} / \mathrm{ml}$ and $0.01515 \pm 0.0016 \mu \mathrm{g} / \mathrm{ml}$, respectively. This survey suggests that ethanol extracts of different parts of $H$. graveolens is an alternative source for natural antioxidant and antimicrobial compounds, urease and tyrosinase inhibitors that could be utilized in drug and food industries.
\end{abstract}

\section{Introduction}

The Helichrysum species are xerophytes growing at altitudes from the sea level up to $1700 \mathrm{~m}$ preferably on sandy or loamy soils. Helichrysum species are commonly recognized as "olmez cicek or altinotu" in Turkish and are widely utilized as herbal tea in Turkey (Bağc1 et al. 2013). Helichrysum graveolens is a medicinal plant which belongs to Asteraceae.

Plants play a substantial role in primary health care as therapeutic medicines in developing countries. Antibiotic resistance as well as appearance of undesirable side effects of some antibiotics (WHO, 2002) has caused to the investigate of alternative antibacterial agents from medicinal plants (Sharma et al. 2012).

Reactive oxygen species (ROS) are continually created inside the human body but excessive or inadequate production of ROS can easily affect antioxidant defense systems. This situation cause many illnesses like cancer, neurodegenerative diseases, arthritis, diabetes mellitus, and ageing process (Patel et al. 2010).

Tyrosinase is a the primary enzyme that catalyzes synthesis of melanin in mammalian, plants and microorganisms cells. Melanin biosynthesis inhibitory compounds are beneficial for skin whitening products utilized in cosmetics and also as a medicine for defects in pigmentation. Plants were acquired attention for cosmetic product improvement because they could have less toxicity than the synthetic ones (Rauniyar et al. 2007).

Antimicrobial, antioxidant, anti-tyrosinase and anti-urease activities and FT-IR analyses of ethanol extracts of flower and stem parts of $H$. graveolens were investigated.

\footnotetext{
*Author for correspondence: <sinem.aydin@ giresun.edu.tr>.
} 


\section{Materials and Methods}

Helichrysum graveolens was collected from the local market of Giresun, Turkey in 2018 (the plant sample was collected from Eğribel passage, Şebinkarahisar) and it was identified by Associate Professor Doctor Zafer Türkmen.
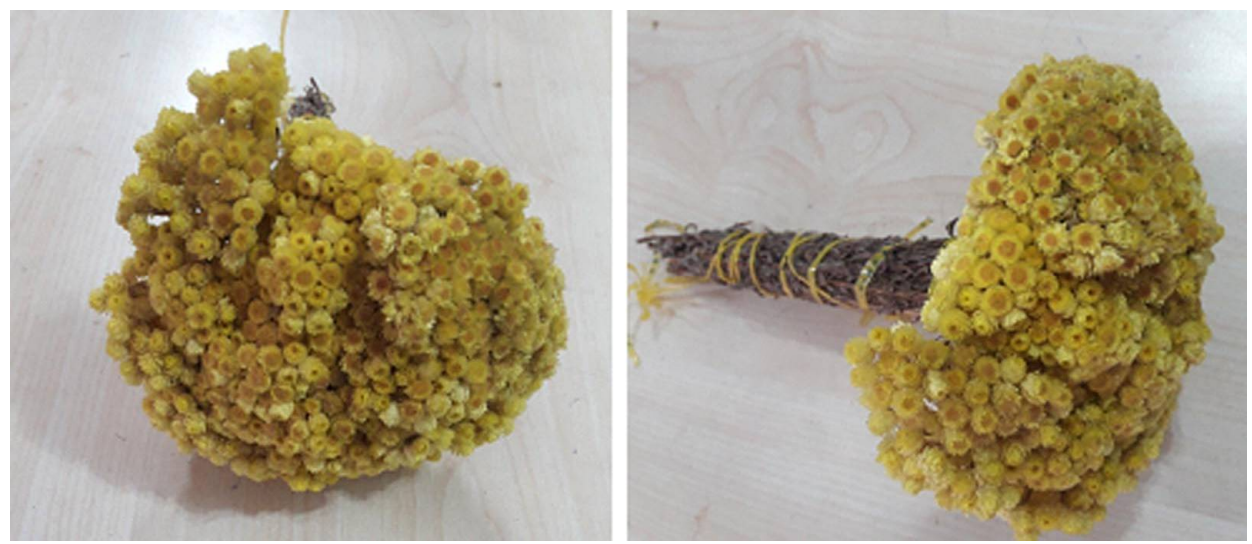

Fig. 1. Helichrysum graveolens

Flower and stem parts of $H$. graveolens were separated, dried on laboratory and then they were grounded into powder, separetely. Twenty gram flower and stem parts of $H$. graveolens were extracted with $200 \mathrm{ml}$ ethanol with a Soxhlet extractor, separetely (Kumar et al. 2012).

In antimicrobial activity assay, the extracts were added into Mueller-Hinton broth at concentration ranging from $0.009765-20 \mathrm{mg} / \mathrm{ml}$. Whereas the mixtures were incubated for bacteria at $37^{\circ} \mathrm{C}$, for fungi the mixtures were incubated for fungi $30^{\circ} \mathrm{C}$ (Yiğit et al. 2009).

Amount of total phenolic compounds (TPC) in the tested extracts was determined using the Folin-Ciocalteu solution according to the method described by Slinkard and Singleton (1977). TPC was expressed as microgram of gallic acid equivalent (GAE) per ml sample by using a calibration graph gallic acid. The tests were performed in triplicate.

Aluminium chloride colourimetric test was utilized to examine the total flavonoid content (TFC) in the extracts (Zhishen et al. 1999). TFC was expressed as microgram of catechin equivalent (CE) per $\mathrm{ml}$ sample by using a calibration graph catechin. TFC in the extracts were worked out in triplicates.

The total antioxidant capacity of the extracts was established by the phosphomolybdenum method (Prieto et al. 1999). Absorbance was measured at $695 \mathrm{~nm}$ using a Shimadzu $1240 \mathrm{UV}$-Vis spectrophotometer (Shimadzu Corporation, Kyoto, Japan). The total antioxidant capacity was expressed as microgram of ascorbic acid equivalent (AAE) per ml sample by using a calibration graph ascorbic acid. The data were presented as the average of triplicate analyses.

The DPPH scavenging activity of ethanol extracts of flower and stem parts of $H$. graveolens was calculated using the following formula (Brand-Williams et al. 1995):

$\%$ Activity: $\left[\frac{A 0=A 1}{A 0}\right] \times 100$

$\mathrm{A}_{0}=$ Absorbance of control, $\mathrm{A}_{1}=$ Absorbance of sample.

CUPRAC test was employed by the method of Özyürek et al. (2009). Butylated hydroxytoluene (BHT) was used as standard antioxidant agent. 
Tyrosinase-inhibitory activity of ethanol extracts of flower and stem parts of $H$. graveolens was determined according to Higuchi et al. (1993). Kojic acid was used as a standard tyrosinaseinhibitor. Urease inhibitory activity was determined according to Van Slyke and Archibald (1944). Thiourea used as standard urease inhibitor agent. The inhibition percentage of anti-tyrosinase and anti-urease activities were calculated from the following equation:

$\%$ Activity: $\left[\frac{A 0-A 1}{A 0}\right] X 100$

$\mathrm{A}_{0}=$ Absorbance of control, $\mathrm{A}_{1}=$ Absorbance of sample.

The $\mathrm{IC}_{50}$ describes as the concentration of inhibitor that decreased urease/tyrosinase activity by $50 \%$ and calculated by plotting the percent of inhibition. The experiments were done triplicate. Lower $\mathrm{IC}_{50}$ values indicate higher enzyme inhibitor activity.

Infra red (IR) analysis was done with the aid of infra red spectrophotometer (JASCO OFTIR 6600 with ATR attachment) at the Central Research Laboratory in Giresun University. A drop of extract was placed carefully on crystal surface. It was fixed on the infra red beam. The infra red data was compared to the table of IR frequencies.

\section{Results and Discussion}

Table 1 summarizes the Minimum Inhibition Concentration (MIC) of ethanol extracts of stem and flower parts of $H$. graveolens. MIC values were found to range from 0.019 to $5 \mathrm{mg} / \mathrm{ml}$ for flower and stem parts. Ethanol extract of stem part of $H$. graveolens exhibited more antibacterial activity against growth of bacteria except for $K$. pneumoniae. When antifungal activity was compared results were similar between stem and flowers parts of $H$. graveolens.

Table 1. MIC values of the extracts $(\mathrm{mg} / \mathrm{ml})$.

\begin{tabular}{lll}
\hline Microorganisms & EFH & ESH \\
\hline Bacillus subtilis IMG 22 & 2.5 & 2.5 \\
Klebsiella pneumoniae (lab isolate) & 0.625 & 2.5 \\
Gordonia rubripertincta (lab isolate) & 2.5 & 1.25 \\
Enterococcus faecalis ATCC 29212 & 2.5 & 1.25 \\
Proteus vulgaris FMC 1 & 2.5 & 1.25 \\
Enterobacter aerogenes CCM 2531 & 2.5 & 0.625 \\
Salmonella enterica ATCC 14028 & 2.5 & 1.25 \\
Candida albicans FMC 17 & 5 & 5 \\
Candida tropicalis ATCC 13803 & 0.019 & 0.019 \\
Candida parapsilosis ATCC 22019 & 2.5 & 1.25 \\
Saccharomyces cerevisiae ATCC 9763 & 0.019 & 0.019 \\
\hline
\end{tabular}

EFH: Ethanol extract of flower part of $H$. graveolens, ESH: Ethanol extract of stem part of $H$. graveolens.

Some studies were performed about antimicrobial activity of $H$. graveolens. For example, Aslan et al. (2007) searched antibacterial activity of petroleum ether and ethanol extracts from the capitula obtained from $H$. graveolens and it was found that ethanol extract of $H$. graveolens had activity against Bacillus cereus, Bacillus megaterium, Streptococcus mutans, Listeria monocytogenes, Escherichia coli, Pseudomonas aeruginosa, Salmonella enteritidis and Shigella sonnei but petroleum extract had activity only against $S$. sonnei. 
Öztürk (2004) demonstrated that methanol extract of $H$. graveolens had higher activity than standard antibiotic ceftazidime against Staphylococcus aureus, E. faecalis and E. cloaceae but weak activity against $E$. coli, $P$. aeruginosa and $S$. thyphimurium. Moreover, it was revealed that methanol extract of $H$. graveolens had no activity against $C$. albicans. On the contrary of this findings, in the present study ethanol extracts of flower and stem parts of $H$. graveolens had activity against $C$. albicans. Smirnov et al. (1982) investigated also antimicrobial activity of $H$. graveolens.

Table 2 shows total phenolic and total flavonoid contents and total antioxidant capacity of stem and flower parts of $H$. graveolens. While total phenolic content and total antioxidant capacity of stem part was higher than flower part, total flavonoid content of flower part was higher than stem part.

The percentage of inhibition of DPPH radical at different concentrations is presented in Table 3. Flower part exhibited higher DPPH radical scavenging activity than stem part of $H$. graveolens. BHT and Rutin possess higher activity than flower and stem parts of $H$. graveolens.

There are studies related about antioxidant activity of $H$. graveolens. For example, according to a study performed by Aslan et al. (2007), total phenolic contents of ethanol and water extracts of $H$. graveolens was found as $91.4 \pm 0.9 \mathrm{mg}$ of GAE/g extract and $70.4 \pm 0.9 \mathrm{mg}$ of GAE/g extract, respectively. Moreover, total flavonoid contents of ethanol and water extracts of $\mathrm{H}$. graveolens was found as $59.5 \pm 3.9 \mathrm{mg}$ of GAE/g extract and $32.7 \pm 1.9 \mathrm{mg}$ of GAE/g extract, respectively. Orhan et al. (2014) revealed that total phenolic contents of aqueous and ethanolic extracts of H. graveolens was $92.9 \pm 2.0 \mathrm{mg} \mathrm{GAE} / 1 \mathrm{~g}$ extract and $139.5 \pm 6.5 \mathrm{mg}$ GAE$/ 1 \mathrm{~g}$ extract, respectively. In the present study, total phenolic and flavonoid contents of ethanol extracts of flower part of $H$. graveolens was detected as $28.85 \pm 0.003 \mu \mathrm{g} \mathrm{GAE} / \mathrm{ml}$ and $59.26 \pm 0.008 \mu \mathrm{g}$ $\mathrm{CE} / \mathrm{ml}$, respectively. The differences between three studies might be arised from collecting plants from different geographical locations.

Table 2. Total phenolic and flavonoid contents and total antioxidant capacity of the extracts.

\begin{tabular}{lccc}
\hline Plant & $\mu \mathrm{g} \mathrm{GAE} / \mathrm{ml}$ & $\mu \mathrm{g} \mathrm{CE} / \mathrm{ml}$ & $\mu \mathrm{g} \mathrm{AAE} / \mathrm{ml}$ \\
\hline $\mathrm{EFH}$ & $28.85 \pm 0.003$ & $59.26 \pm 0.008$ & $66.85 \pm 0.024$ \\
$\mathrm{ESH}$ & $41.41 \pm 0.017$ & $50.21 \pm 0.005$ & $128.65 \pm 0.022$ \\
\hline
\end{tabular}

Value represents mean of three replicates.

Table 3. DPPH scavenging activity of the extracts (\% inhibition).

\begin{tabular}{ccccc}
\hline $\begin{array}{c}\text { Concentration } \\
(\mu \mathrm{g} / \mathrm{ml})\end{array}$ & EFH & ESH & BHT & Rutin \\
\hline 50 & $14.77 \pm 0.032$ & $8.72 \pm 0.037$ & $80.22 \pm 0.015$ & $58.31 \pm 0.025$ \\
100 & $32.25 \pm 0.012$ & $26.91 \pm 0.014$ & $84.49 \pm 0.013$ & $61.08 \pm 0.003$ \\
150 & $48.20 \pm 0.019$ & $41.02 \pm 0.018$ & $88.09 \pm 0.003$ & $64.28 \pm 0.002$ \\
200 & $61.36 \pm 0.021$ & $53.93 \pm 0.012$ & $94.06 \pm 0.003$ & $75.57 \pm 0.013$ \\
\hline
\end{tabular}

Value represents mean of three replicates.

Table 4 presents CUPRAC activity of the extracts. Stem part of $H$. graveolens exhibited higher activity than flower part of $H$. graveolens. BHT which used as standard antioxidant showed considerably higher activity than $H$. graveolens. 
Table 4. CUPRAC activity of the extracts $(\mathrm{nm})$.

\begin{tabular}{cccc}
\hline Concentration $(\mu \mathrm{g} / \mathrm{ml})$ & EFH & ESH & BHT \\
\hline 50 & $0.122 \pm 0.001$ & $0.133 \pm 0.016$ & $0.552 \pm 0.028$ \\
100 & $0.152 \pm 0.003$ & $0.155 \pm 0.007$ & $0.920 \pm 0.027$ \\
150 & $0.163 \pm 0.005$ & $0.170 \pm 0.002$ & $1.068 \pm 0.014$ \\
200 & $0.173 \pm 0.001$ & $0.180 \pm 0.002$ & $1.130 \pm 0.025$ \\
\hline
\end{tabular}

Value represents mean of three replicates.

Öztürk (2004) determined that DPPH scavenging activity of methanol extracts (with a range from 52.06 to $78.21 \%$ ) of $H$. graveolens which were collected from different locations. Moreover, total antioxidant capacity of methanol extracts of $H$. graveolens which were collected from different locations was found to range from $7.8893 \mathrm{mmol} \alpha$-tocopherolacetate/mg extract to $9.7666 \mathrm{mmol} \alpha$-tocopherolacetate/mg extract. In the present study, it was found that DPPH scavenging activity of ethanol extract of flower part of $\mathrm{H}$. graveolens ranged from 14.77 to $61.36 \%$ and DPPH scavenging activity of ethanol extract of stem part of $H$. graveolens ranged from 8.72 to $53.93 \%$. Moreover, total antioxidant capacity was detected as $66.85 \pm 0.024 \mu \mathrm{g}$ $\mathrm{AAE} / \mathrm{ml}$ for flower part and $128.65 \pm 0.022 \mu \mathrm{g}$ AAE/ml for stem part. The difference might be due to the use of different solvents and different plant parts in assays and collecting plant samples from different locations.

Table 5 shows anti-urease and anti-tyrosinase activities of $H$. graveolens. Flower part of $H$. graveolens showed slightly higher activity than stem part of H. graveolens. Moreover, kojic acid exhibited higher activity than tested plant parts. When anti-urease activity of the plant parts was compared, stem part showed higher activity than flower part. In addition to this, stem part demonstrated higher activity than thiourea which used standard anti-urease agent.

Table 5. Anti-urease and anti-tyrosinase activities of stem and flower parts of $\boldsymbol{H}$. graveolens and standards.

\begin{tabular}{lllll}
\hline Plant & $\begin{array}{c}\text { Concentration } \\
(\mu \mathrm{g} / \mathrm{ml})\end{array}$ & $\mathrm{IC}_{50}$ & $\begin{array}{c}\text { Concentration } \\
(\mu \mathrm{g} / \mathrm{ml})\end{array}$ & $\mathrm{IC}_{50}$ \\
\hline Stem & 0.00001 & $0.01549 \pm 0.0006$ & 0.00001 & $0.0082 \pm 0.0008$ \\
& 0.0001 & & 0.0001 & \\
& 0.001 & & 0.001 & \\
Flower & 0.01 & & 0.01 & \\
& 0.00001 & $0.01515 \pm 0.0016$ & 0.00001 & $0.0108 \pm 0.0012$ \\
& 0.0001 & & 0.0001 & \\
Thiourea & 0.001 & & 0.001 & \\
& 0.01 & & 0.01 & \\
& 0.00001 & & 0.00001 & $0.00909 \pm 0.00005$ \\
& 0.0001 & & 0.0001 & \\
Kojic acid & 0.001 & & 0.001 & \\
& 0.01 & & 0.01 & \\
& 0.00001 & $0.0088 \pm 0.0002$ & 0.00001 & \\
& 0.0001 & & 0.0001 & \\
& 0.001 & & 0.001 & \\
& 0.01 & & 0.01 & \\
\hline
\end{tabular}


This is the first report about anti-urease activity of stem and flower parts of $H$. graveolens.

Table 6 presents results of FT-IR analyses of ethanolic extract of flower part of $H$. graveolens. (Table 6, Fig. 2). The absorptions in the frequencies $2800-3000 \mathrm{~cm}^{-1}$ were due to $\mathrm{C}-\mathrm{H}$ stretching vibrations that are mainly generated by alcohol or phenols. The band at $2923.56 / \mathrm{cm}$ are assigned to aliphatic $\mathrm{CH}$ stretching which possibly due to the presence of alkanes. The vibration at frequencies $1500-1600 / \mathrm{cm}$ indicates the presence of aromatic ring compound so $1504.48 / \mathrm{cm}$ and $1508.06 / \mathrm{cm}$. The absorptions in this region were due to the presence of aromatic $\mathrm{C}=\mathrm{C}$ bond. The bands at $1446.35 / \mathrm{cm}$, stretching assigned to $\mathrm{C}-\mathrm{H}$ in-plane bending. which indicated the presence of alkanes. The presence these functional groups in $H$. graveolens make it a potential pharmacological source for new antibacterial, antioxidant and anti-tyrosinase agents (Rajiv et al. 2017, Oladunmoye et al. 2018).

Table 7 presents results of FT-IR analyses of ethanolic extract of stem part of $H$. graveolens. (Table 7, Fig. 3). 2915.04/cm and 2854.13/cm absorbtion bands corresponds the presence of alkanes and absorption band at $3324.68 / \mathrm{cm}$ revealed the presence of alcohols and phenols in the tested ethanol extract. The band at $1052.94 / \mathrm{cm}$ are assigned to $\mathrm{C}-\mathrm{O}$ streching which possibly due to the presence of alcohol, carboxylic acid, esther and ether. The $\mathrm{C}-\mathrm{H}$ stretching due to alkanes was observed at $1423.21 / \mathrm{cm}$. The vibration at frequencies $1500-1600 / \mathrm{cm}$ represents aromatic ring compound so the bands at $1612.2 / \mathrm{cm}$ indicated aromatic $\mathrm{C}=\mathrm{C}$ streching (Rajiv et al. 2017, Oladunmoye et al. 2018).

Table 6. Results of FT-IR analysis of ethanol extract of flower parts of $\boldsymbol{H}$. graveolens.

\begin{tabular}{ll}
\hline Wave numbers & Bond \\
\hline 3286.11 & OH stretching \\
2923.56 & Alifatic $\mathrm{CH}$ stretching \\
2352.73 & $\mathrm{C}=\mathrm{N}$ or $\mathrm{C}=\mathrm{C}$ bond \\
1504.48 & Aromatic $\mathrm{C}=\mathrm{C}$ bond \\
1508.06 & Aromatic $\mathrm{C}=\mathrm{C}$ bond \\
1446.35 & $\mathrm{C}-\mathrm{H}$ in-plane bending \\
1349.93 & OH stretching \\
1033.66 & C-O stretching \\
\hline
\end{tabular}

Table 7. Results of FT-IR analysis of ethanol extract of stem part of $\mathrm{H}$. graveolens.

\begin{tabular}{ll}
\hline Wave numbers & Bond \\
\hline 3324.68 & OH stretching \\
2915.04 & Alifatic C-H stretching \\
2854.13 & Alifatic C-H stretching \\
2352.73 & C=N or C=C bond \\
1612.2 & Aromatic C=C stretching \\
1423.21 & C-H in-plane bending \\
1261.22 & O-H stretching \\
1052.94 & C-O stretching \\
\hline
\end{tabular}




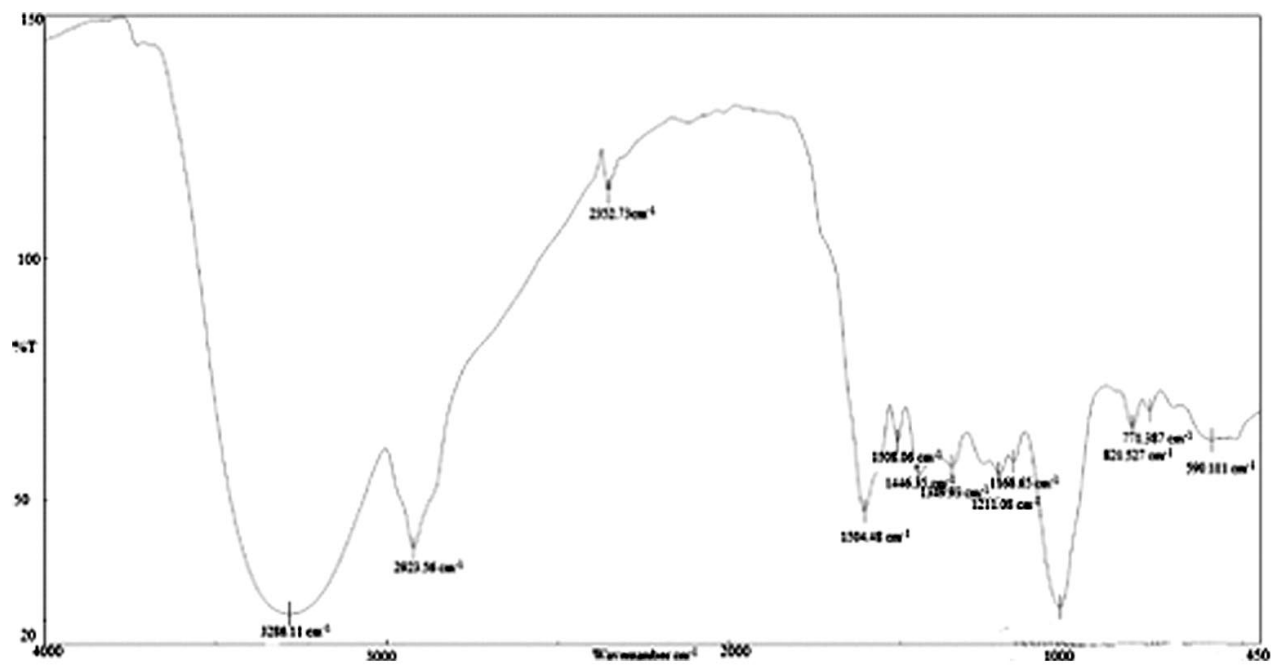

Fig. 2. FT-IR analysis of ethanol extract of flower part of $H$. graveolens.

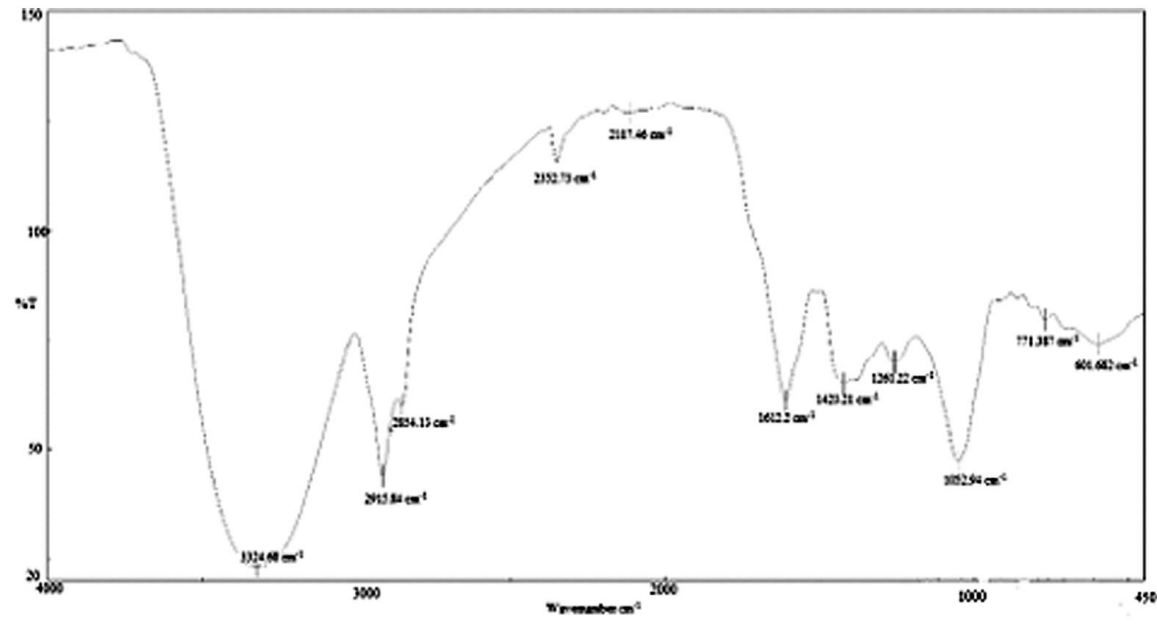

Fig. 3. FT-IR analysis of ethanol extract of stem parts of $H$. graveolens.

From the present it is revealed that ethanol extracts of flower and stem parts of $H$. graveolens possess important antimicrobial, antioxidant, anti-tyrosinase and anti-urease effects and this plant could be an alternative to synthetic antimicrobial, antioxidant, anti-tyrosinase and anti-urease agents but further investigations require to carried out to detect active ingredients responsible for their antimicrobial, antioxidant, anti-tyrosinase and anti-urease effects which found in $H$. graveolens.

\section{Acknowledgements}

The author is grateful to Assistant Professor Doctor Öznur Ölmez NALCIOĞLU for helping FT-IR analyses reviews of the plant extracts. He also wishes to thank Associate Professor Doctor Zafer TÜRKMEN for identifying plant sample. 


\section{References}

Aslan M, Katırcıoğlu H, Orhan I, Atıcı T and Sezik E 2007. Antibacterial potential of the capitula of eight Anatolian Helichrysum species. Turk. J. Pharm. Sci. 4(2): 71-77.

Aslan M, Orhan DD, Orhan M, Sezik E and Yeşilada E 2007. A study of antidiabetic and antioxidant effects of Helichrysum graveolens capitulums in streptozotocin-induced diabetic rats. J. Med. Food 10(2): 396400.

Bağcı E, Elkıran Ö and Evren H 2013. Constituents of the essential oils of Helichrysum graveolens (Bieb.) Sweet from Turkey. Asian J. Chem. 25(13): 7254-7256.

Brand-Williams W, Cuvelier ME and Berset C 1995. Use of a free radical method to evaluate antioxidant activity. LWT Food Sci. Technol. 28: 25-30.

Higuchi M, Miura Y, Boohene J, Kinoshita Y, Yamamoto Y, Yoshimura I and Yamada Y 1993. Inhibition of tyrosinase activity by cultured lichen tissues and bionts. Planta. Med. 59: 253-255.

Kumar S, Dhankhar S, Arya VP, Yadav S and Yadav JP 2012. Antimicrobial activity of Salvadora oleoides Decne against some microorganisms. J. Med. Plants Res. 6(14): 2754-2760.

Oladunmoye MK, Ayantola KJ, Agboola AA, Olowe BM and Adefemi OG 2018. Antibacterial and Ft-Ir spectral analysis of methanolic extract of Gliricidia sepium leaves. J. Adv. Microbiol. 9(4): 1-10.

Orhan N, Hoşbaş S, Orhan DD, Aslan M and Ergun F 2014. Enzyme inhibitory and radical scavenging effects of some antidiabetic plants of Turkey. Iran. J. Basic Med. Sci. 17(6): 426-432.

Öztürk B 2004. Comparison of flavonoid and flavor oil contents of Turkish Helichrysum's and their antioxidant, antimicrobial efficiency potentials. PhD Thesis, Ege University, Health Sciences Institue, İzmir, pp. 258.

Özyürek M, Bektaşoğlu B, Güçlü K and Apak R 2009. Measurement of xanthine oxidase inhibition activity of phenolics and flavonoids with a modified cupric reducing antioxidant capacity (CUPRAC) method. Anal. Chim. Acta. 636(1): 42-50.

Patel VR, Patel PR and Kajal SS 2010. Antioxidant activity of some selected medicinal plants in Western Region of India. Adv. Biol. Res. 4(1): 23-26.

Prieto P, Pineda M and Anguilar M 1999. Spectrophotometric quantitation of antioxidant capacity through the formation of a phosphomolybdenum complex: specific application to the determination of vitamin $\mathrm{E}$. Anal. Biochem. 269: 337-341.

Rajiv P, Deepa A, Vanathi P and Vidhya D 2017. Screening for phytochemicals and FTIR analysis of Myristica dactyloids fruit extracts. Int. J. Pharm. Pharm. Sci. 9(1): 315-318.

Rauniyar R, Talkad MS, Sahoo S, Singh A and Harlalka P 2007. Anti-tyrosinase activity of Stachytarpheta cayennensis in vitro. Int. J. Innov. Res. Sci. Eng. Technol. 3(7): 14259-14266.

Sharma A, Meena A and Meena R 2012. Antimicrobial activity of plant extracts of Ocimum tenuiflorum. Int. J. PharmTech Res. 4(1): 176-180.

Smirnov VV, Preobrazhenskaia NE, Ovdienko AA, Bondasenka AK and Kalashnikov ID 1982. Antimicrobial properties of Helichrysum graveolens (MB) Sweet. Mikrobiol. Zh. 44(6): 84-87.

Slinkard K and Singleton VL 1977. Total phenol analysis: automation and comparison with manual methods. Am. J. Enol. Viticult. 28: 49-55.

Van Slyke DDE and Archibald RM 1944. Manometric, titrimetric and colorimetric methods for measurement of urease activity. J. Biol. Chem. 154: 623-642.

Yiğit D, Yiğit N, Aktaş E and Özgen U 2009. Ceviz (Junglans regia L.)' in antimikrobiyal aktivitesi. Türk Mikrobiyol. Cem. Derg. 39 (1-2): 7-11.

Zhishen J, Mengcheng T and Jianming W 1999. The determination of flavonoid contents in mulberry and their scavenging effects on superoxide radicals. Food Chem. 64: 555-559. 